\title{
PRACTISE - Photo Rectification And ClassificaTIon SoftwarE (V.2.1)
}

\author{
S. Härer, M. Bernhardt, and K. Schulz \\ Institute of Water Management, Hydrology and Hydraulic Engineering (IWHW), University of Natural Resources \\ and Life Sciences (BOKU), Vienna, Austria
}

Correspondence to: S. Härer (stefan.haerer@boku.ac.at)

Received: 5 August 2015 - Published in Geosci. Model Dev. Discuss.: 5 October 2015

Revised: 7 January 2016 - Accepted: 11 January 2016 - Published: 26 January 2016

\begin{abstract}
Terrestrial photography combined with the recently presented Photo Rectification And ClassificaTIon SoftwarE (PRACTISE V.1.0) has proven to be a valuable source to derive snow cover maps in a high temporal and spatial resolution. The areal coverage of the used digital photographs is however strongly limited. Satellite images on the other hand can cover larger areas but do show uncertainties with respect to the accurate detection of the snow covered area. This is especially the fact if user defined thresholds are needed, e.g. in case of the frequently used normalizeddifference snow index (NDSI). The definition of this value is often not adequately defined by either a general value from literature or over the impression of the user, but not by reproducible independent information. PRACTISE V.2.1 addresses this important aspect and shows additional improvements. The Matlab-based software is now able to automatically process and detect snow cover in satellite images. A simultaneously captured camera-derived snow cover map is in this case utilized as in situ information for calibrating the NDSI threshold value. Moreover, an additional automatic snow cover classification, specifically developed to classify shadow-affected photographs, was included. The improved software was tested for photographs and Landsat 7 Enhanced Thematic Mapper (ETM+) as well as Landsat 8 Operational Land Imager (OLI) scenes in the Zugspitze massif (Germany). The results show that using terrestrial photography in combination with satellite imagery can lead to an objective, reproducible, and user-independent derivation of the NDSI threshold and the resulting snow cover map. The presented method is not limited to the sensor system or the threshold used in here but offers manifold application options for other scientific branches.
\end{abstract}

\section{Introduction}

Snow cover plays an important role in the Earth's climate system as direct feedback mechanisms between surface temperature, surface albedo, and snow cover exist (IPCC, 2013). These reinforcing feedback processes have significantly contributed to the observed decrease in spring snow cover in the Northern Hemisphere in the last decades (Groisman et al., 1994; IPCC, 2013). Despite this general trend in the Northern Hemisphere, the observed seasonal and altitudinal variations in snow cover changes are large for different regions (Brown and Mote, 2009). Regional studies are thus crucial to provide a more complete picture. This is of special importance for high elevation areas where large amounts of water are temporally stored as snow and which therefore supply the lowlands with fresh water during the snowmelt in spring and summer (Viviroli et al., 2007, 2011).

However, station data of snow cover in alpine regions are rare except for a few well-equipped sites (Scherrer et al., 2004; Marty, 2008; Viviroli et al., 2011; Pomeroy et al., 2015). Manual in situ measurements are often prevented for reasons of remoteness and safety by the harsh environmental conditions (Klemes, 1990). Satellite remote sensing techniques are a big step forward in these data-scarce areas but it is still a challenge to achieve snow cover products with high spatial and temporal resolutions as well as a high accuracy (Klemes, 1990; Viviroli et al., 2011). The complementary use of ground and space borne measurements for observing mountainous snow cover as highlighted by Vivirioli et al. (2011) is a promising approach and the main motivation behind this paper.

Terrestrial photography is thereby utilized as ground truth data. This technique has been successfully applied in many 
applications in the context of glaciology and snow hydrology (Corripio, 2004; Rivera et al., 2008; Dumont et al., 2009; Garvelmann et al., 2013; Messerli and Grinsted, 2015; cf. Parajka et al., 2012 for an overview). The advantages of terrestrial photography are that this technique has a high accuracy, is non-invasive, and provides spatially distributed snow cover data in a high temporal and spatial resolution (Aschenwald et al., 2001; Hinkler et al., 2002; Corripio et al., 2004; Schmidt et al., 2009; Parajka et al., 2012; Härer et al., 2013). The decreasing costs of digital cameras and camera lenses with no or minimal distortion, as well as the potential use of terrestrial photography in remote and hostile environments due to technical advancements in off-grid power supply and data transfer also need to be mentioned here.

The alpine snow cover patterns derived from terrestrial photography can then be used to evaluate spatially distributed (snow-) hydrological models like Alpine3D, SnowModel, and others (Lehning et al., 2006; Liston and Elder, 2006; Bernhardt et al., 2012). The high spatial resolution of the photograph snow cover maps is very valuable, as snow cover strongly varies over time and space and an accurate description in models is difficult (Blöschl et al., 1991; Winstral and Marks, 2002; Bernhardt and Schulz, 2010). The high temporal resolution of the terrestrial camera systems, for example on an hourly basis, further enhances the probability of at least one suitable photograph per day, despite the frequently occurring cloud and precipitation events at high altitudes (Härer et al., 2013).

To map the spatial snow cover distributions, the recorded 2-D photographs have to be classified and georectified. Corripio (2004) and Corripio et al. (2004) presented a software tool that eased the georectification process, utilizing the animation and rendering technique by Watt and Watt (1992). This also formed the basis for the Photo Rectification And ClassificaTIon SoftwarE (PRACTISE V.1.0; Härer et al., 2013). Though, the formulations for the calculation of the 3 -D rotation and projection are slightly different to Corripio (2004) and Corripio et al. (2004). PRACTISE V.1.0 further simplifies and fastens the spatially distributed monitoring of snow cover patterns in mountainous terrain as it includes in addition to the georectification module routines for the identification of camera location and orientation, the viewshed computation and the snow classification of photographs. A batch mode also allows the processing of several photographs and thus the generation of multiple snow cover maps in a single program evaluation.

The trade-off for the high spatial resolution snow cover maps from terrestrial photography is that these maps are restricted to a comparatively small region. To monitor a complete catchment with an extent of several square kilometres and more, satellite imagery is more suitable. These data have a lower spatial and temporal resolution but it offers the advantage of long consistent time series and the coverage of large areas. The normalized-difference snow index (NDSI) formulated by Dozier in 1989 for Landsat data is thereby still a standard method to derive snow cover maps (cf. SNOMAP algorithm of the MODIS snow cover product; Hall et al., 2001; Hall and Riggs, 2007). Other promising methods like traditional supervised multispectral classifications, artificial neural networks or spectral-mixture analyses are computationally highly intensive, need lots of additional input data or are dependent on the interpreter's knowledge (Hall et al., 2001). These techniques are thus difficult to automate.

The NDSI represents the space borne component in the synthesis of ground and satellite measurements in this study. The index relies on a band rationing technique with a simple but effective principle that snow is highly reflective in the visible bands (GREEN, $\sim 0.55 \mu \mathrm{m}$ ) while having a very low reflectance in the mid-infrared bands (MIR; $\sim 1.6 \mu \mathrm{m}$; Dozier, 1989). In this approach, it is assumed that snow is present within a satellite pixel if the NDSI is greater than 0.4 ,

$\mathrm{NDSI}=\frac{\text { GREEN }- \text { MIR }}{\text { GREEN }+ \text { MIR }}>0.4$,

and the near infrared (NIR; $\sim 0.85 \mu \mathrm{m}$ ) reflectance value is above 0.11 ,

NIR > 0.11 (Dozier, 1989; Hall et al., 1995).

The NIR condition ensures that water surfaces, which can also have high NDSI values, are not misclassified as snow.

The NDSI threshold value of 0.4 is the standard literature value (Nolin, 2010; Dietz et al., 2012) even though Hall et al. (1995) already mention that acceptable snow cover maps were found for NDSI thresholds between 0.25 and 0.45 in a study investigating six scenes in the United States and Iceland. This threshold range corresponded to changes in snow cover extent of more than $10 \%$ in the studied scenes. In particular for local and regional applications it is thus crucial to set the NDSI threshold accurately but in a userfriendly and standardized manner. The manual adjustment of the threshold is no option in most cases as it is not reproducible and offers the danger of adapting the resulting snow cover distribution to support a given hypothesis.

This paper presents a new method to monitor alpine snow cover patterns with satellite data by making use of terrestrial camera infrastructure, including webcams. The NDSI threshold value for snow is thereby calibrated to achieve an optimal agreement in the overlapping area of the photograph and satellite snow cover maps. Hence, an optimal NDSI-based satellite snow cover map for the specific region and time is produced, for example for an alpine catchment with an extent of several square kilometres. The cameras needed for this method are often already available or can be easily installed at many sites. We focus on Landsat data in here, as the pixel dimensions of $30 \mathrm{~m}$ are in comparison to MODIS pixel sizes of $500 \mathrm{~m}$ preferable for local and regional applications, particularly as the instantaneous field of view further increases for mountainous terrain with steep slopes. 
The new approach to complementary use ground and space borne measurements to derive snow cover maps is fully implemented in PRACTISE V.2.1. The fast and easy-to-use processing includes the NDSI calculation from Landsat raw data as well as the use of NDSI maps produced externally in geoinformation systems. Optionally, it also allows for including an existing cloud mask using for example the freely available Fmask software (Zhu et al., 2015). In addition, a newly developed snow classification algorithm for shadow-affected photographs is presented in PRACTISE V.2.1. Further improvements are bug fixes and revised code of already published modules as well as increased user friendliness.

This paper is supplemented with an example data set, a manual and the associated Matlab code. The structure of the paper itself is as follows: at first, the test site and data are described. The newly developed modules and improvements in existing modules of the software are subsequently explained. Then, the resulting snow cover maps of exemplary photographs and Landsat satellite images are presented and discussed for the test area. Finally, a conclusion and an outlook are given.

\section{Test site and data}

PRACTISE (V.2.1) was developed and tested in the Zugspitze massif, Germany. The investigated Zugspitzplatt covers a surface area of $13.1 \mathrm{~km}^{2}$. A common single lens reflex camera (SLR; Canon EOS 550D, Canon EF 17-40 mm f/4I USM objective lens, 17.9 Mpx) directed towards the north-east facing slope of the Schneefernerkopf and a webcam (Mobotix M10 L43, 1.2 Mpx) observing the southeastern area of the Zugspitzplatt are used (Fig. 1). Both cameras take hourly photographs during daylight and are installed at the Environmental Research Station Schneefernerhaus (UFS; 2650 ma.s.l.). We refer the reader to Bernhardt et al. (2014) for more information on the research station.

\subsection{General input data of PRACTISE V.2.1}

PRACTISE V.2.1 requires a digital elevation model (DEM) and the exterior orientation parameters of the camera, i.e. the camera position $\boldsymbol{C}$, the camera target position $\boldsymbol{T}$ and the roll $\xi$ of the camera, as input. By definition, the camera target position is the location shown in the centre of the photograph. The latitude and longitude positions of $\boldsymbol{C}$ and $\boldsymbol{T}$ are sufficient as input, as the altitude is taken from the corresponding DEM pixel during the computing process. If necessary, a camera offset $o$ (installation height above the surface) is added to the altitude of $\boldsymbol{C}$, the combined altitude being referred to as $\boldsymbol{C}_{\mathrm{o}}$. Similarly, a camera target offset $t$ can be added to the elevation of $\boldsymbol{T}$ if $\boldsymbol{T}$ is not located inside the DEM. The combined value is referred to as $\boldsymbol{T}_{\mathrm{t}}$. In addition, interior orientation parameters of the camera are necessary, such as the focal length $f$, as well as the sensor dimensions: height $h$ and width $w$ (Härer et al., 2013). The ver-

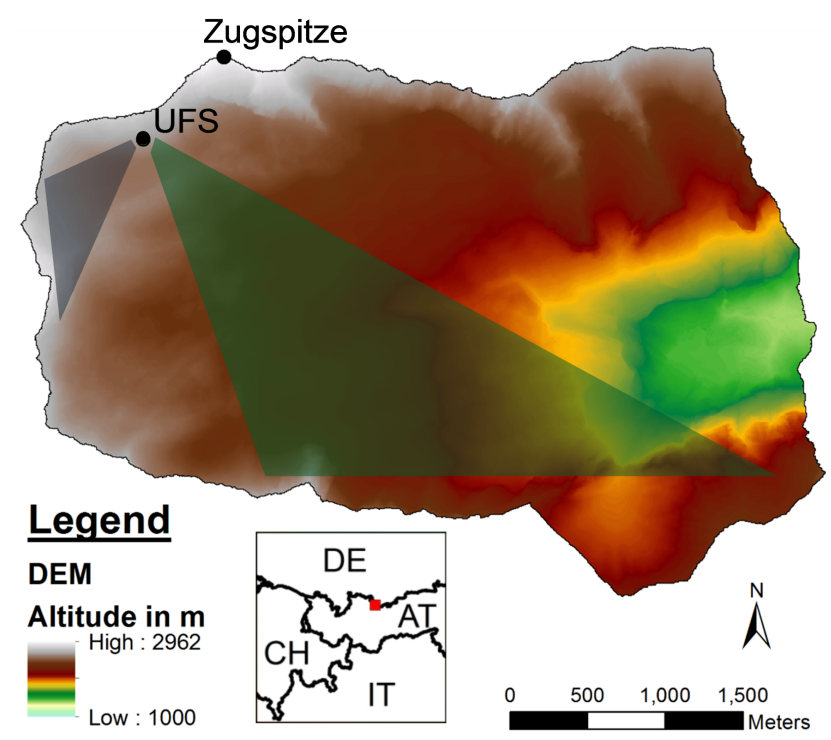

Figure 1. DEM of the Zugspitzplatt catchment at the border of Germany and Austria and the sketched fields of view of the cameras installed at the Environmental Research Station Schneefernerhaus (UFS; $2650 \mathrm{~m}$ ): the single lens reflex camera (SLR) monitors Schneefernerkopf summit in the south-west of the UFS (blue) and the webcam is directed towards the south-eastern Zugspitzplatt area (green).

tical and horizontal dimensions of the photograph $\left(N_{\mathrm{v}}\right.$ and $N_{\mathrm{h}}$ ) are also needed for the georectification. These values are automatically derived by the software. We want to note here that lens distortions are not taken into account in PRACTISE as there are commercial and open-source software packages (e.g. PTLens, http://epaperpress.com/ptlens/ and LensFun, http://lensfun.sourceforge.net/) for the pre-processing of distorted photographs available.

The abovementioned inputs are obligatory in PRACTISE independent of the used modules. However, the camera parameters can also be estimated and automatically optimized if ground control points (GCPs) are available. The use of an externally calculated viewshed is optional if all exterior and interior camera parameters are known. Snow classification parameters are another required input in PRACTISE but only for the selected classification routine (cf. Sect. 3.1 and Härer et al., 2013). If the satellite image module is in use, radiometrically and geometrically corrected data of Landsat 5 Thematic Mapper (TM), Landsat 7 Enhanced Thematic Mapper Plus (ETM+), or Landsat 8 Operational Land Imager (OLI) can be processed. Instead of Landsat Level 1 data, the use of externally generated satellite NDSI maps is possible here. The spatial processing extent is user-dependent as well as if an externally produced mask for clouds, (cloud) shadows, and water is used or not. Another optional input is a Landsat Look image for visualization. 


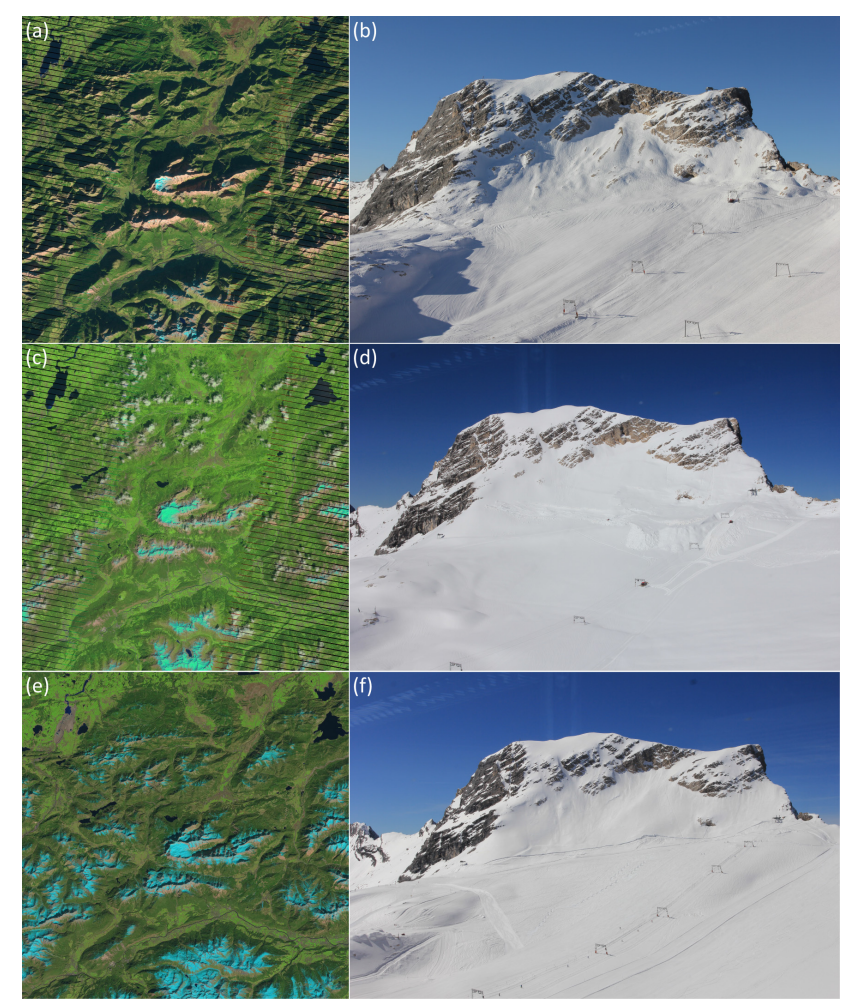

Figure 2. Enlarged view of the Landsat Look images of Zugspitzplatt (in the centre) and SLR photographs of Schneefernerkopf for 17 November 2011 (a, b), 1 July 2013 (c, d), and 7 April 2014 $(\mathbf{e}, \mathbf{f})$ : snow cover extents are generally depicted in cyan colours in the Landsat scenes. (a, b) show about 1 month old snow with strong shadowing effects and some partial cloud coverage (not visible in the Landsat Look image). (c) and (d) display fresh snow and have a significant but partial cloud coverage. (e) and (f) also show fresh snow but under clear conditions and with some weak shadowing effects.

\subsection{Study-specific input data of PRACTISE V.2.1}

The functionality of the new modules of PRACTISE V.2.1 will be demonstrated on the basis of photographs and Landsat satellite images of 17 November 2011, 1 July 2013 and 7 April 2014. The dates were chosen because they represent different snow and illumination conditions at Zugspitzplatt as well as different snow cover extents and cloud coverages (Fig. 2a-f). The scenes are therefore suited to test the capabilities of PRACTISE with respect to changing surrounding conditions.

SLR photographs are available for all dates while webcam images are available for 2013 and 2014. Landsat 7 overflights have captured the test site in 2011 and 2013 (Fig. 2a and c), Landsat 8 in 2014 (Fig. 2e). Masks for clouds, shadows, and cloud shadows as well as water bodies were externally generated with the Fmask algorithm of Zhu et al. (2015). The masks are applied for the scenes on 17 November 2011 and on 1 July 2013 whereas the cloud cover is not visible in the
Landsat Look image on 17 November 2011. We also want to note here that Landsat 7 imagery is affected by a failure of the Scan Line Corrector (SLC) that normally compensates for the forward motion of the Landsat satellite from 31 May 2003 onwards. But, Zugspitzplatt area is located in the centre of the scene and is therefore not affected by this error.

The inputs given for the georectification of the SLR and webcam photographs are presented in Table 1. Cameradependent parameters were taken from the user manual of the camera systems. The focal lengths have been adjusted according to the used image. The location and target position of the camera, as well as the GCP locations have been identified combining photographs, DEM data, topographical maps and official orthophotos with a sub-metre spatial resolution. Nevertheless, the camera location and target position could only be estimated. The camera parameters in Table 1 except the camera sensor and photograph dimensions thus need to be optimized using GCPs. A separate estimation for each photograph in this study is further necessary as the locations and orientations of the cameras are changing in between the photographs due to either weather effects like wind, for maintenance reasons, or a new camera location at the UFS.

The DEM used for the SLR photographs has a spatial resolution of $1 \mathrm{~m}$ in the horizontal plane and originated from an airborne laser scanning (ALS) campaign in 2006 by the Martin Luther University, Halle-Wittenberg, Germany. The DEM was resampled to a $5 \mathrm{~m}$ resolution for processing the webcam photographs. The resampling can be seen as an adjustment to the lower webcam resolution. Both DEM are referenced to the coordinate system of the Landsat images, which is the Universal Transverse Mercator (UTM) system based on the World Geodetic System 1984 (WGS84).

\section{Model routines}

PRACTISE V.2.1 introduces two major enhancements compared to version 1.0; the snow classification in partially shadow-affected photographs (Sect. 3.1) and the threshold calibration for optimal NDSI-based snow cover maps (Sect. 3.2). In addition, all existing routines have been refined with respect to performance and user friendliness (Sect. 3.3). The new routines (Sect. 3.1 and 3.2) and the flow chart (Sect. 3.3) of PRACTISE V.2.1 will be exemplarily presented for a SLR photograph and a Landsat 7 ETM+ image of Zugspitzplatt on 17 November 2011.

\subsection{Snow classification in partially shadow affected photographs}

PRACTISE V.1.0 provides two snow classification routines for terrestrial RGB photographs. The user can select between a manual routine, which basically detects snow for digital numbers (DN) above user-specific snow thresholds in the red, green, and blue (RGB) bands of the digital photograph 
Table 1. Estimated parameters of the exterior and interior camera orientation of the SLR and webcam before the optimization: the parameter ranges in the optimization for the cameras and dates are given as differences in $\mathrm{m}$ except noted otherwise to the estimated values. For the webcam photograph on 7 April 2014, the camera is directed towards an area outside of the DEM. Hence, the optimization of the camera target point offset $t$ and an enlarged parameter range for the camera target point $\left(\boldsymbol{T}_{\mathrm{t}}\right)$ is necessary.

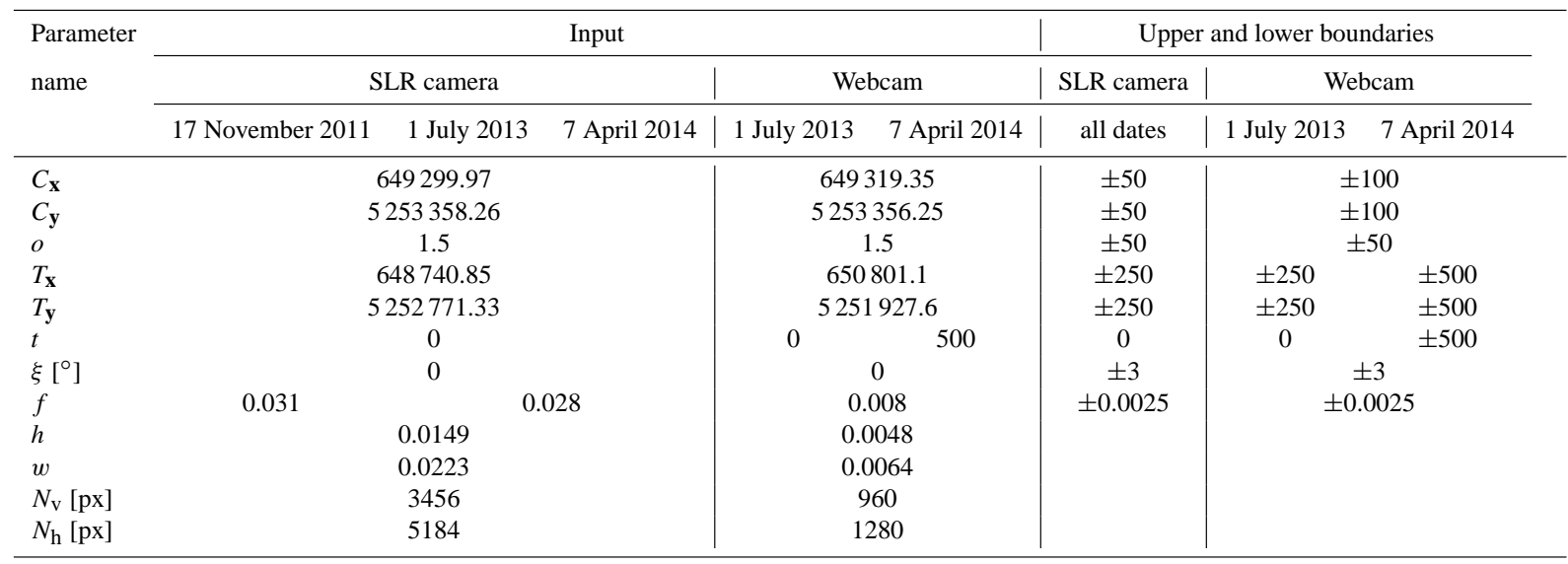

and an algorithm developed by Salvatori et al. (2011). This algorithm is a threshold based procedure, which automatically analyses the blue band DN frequency histogram and sets the snow threshold. Both classification types of PRACTISE V.1.0 are described in detail in Härer et al. (2013).

Both algorithms are working well if the photography is evenly illuminated and in the absence of shadows (Härer et al., 2013). However, shadow-free situations are rare in structured terrain and clouds can reason further shadowing. In the case of shaded areas, the two included classification routines tend to only identify snow surfaces that are sunlit while the classification in shaded areas has high uncertainties. This results from similarly high blue band DN in RGB images for shaded snow cover, and illuminated rock, soil, or sparsely vegetated surfaces (Fig. 3a and b).

PRACTISE V.2.1 therefore includes a new classification routine, which automatically detects snow in shadowaffected photographs. The algorithm includes the automatic blue band classification from PRACTISE V.1.0 to identify the sunlit snow cover in the RGB images and additionally uses a principal component analysis (PCA) for separating shaded snow cover from sunlit rock surfaces. The method was developed analysing photographs in the Zugspitzplatt catchment and in the Vernagtferner area, Austria. The routine will be presented for the SLR photograph on 17 November 2011.

In a first step the algorithm of Salvatori et al. (2011) described in Härer et al. (2013) is used for classifying snow at sunny locations. Snow cover detected in this step is illustrated in red in Fig. 4.

The second step in the classification routine is the utilization of a PCA to detect snow cover in shaded areas. The PCA is a statistical method to analyse multivariate data sets. In our case, we use the PCA to orthogonally transform the axes of the RGB space to a new principal component (PC) space

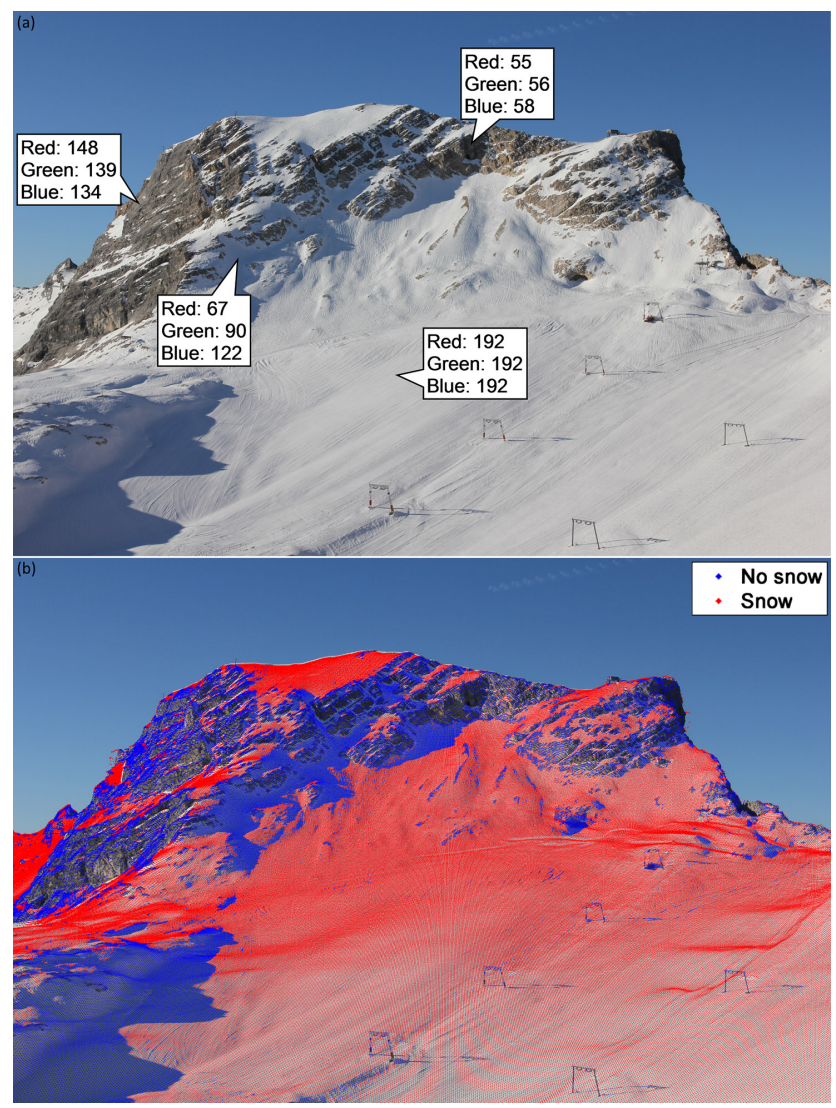

Figure 3. SLR photograph of Schneefernerkopf with large shadows on 17 November 2011: (a) the outlined RGB values ( 8 bit data, from 0 to 255) for the different surfaces show similarly high blue band values for shaded snow cover and illuminated rock areas. (b) Hence, shaded snow cover is erroneously classified as free of snow in the algorithm of Salvatori et al. (2011). 


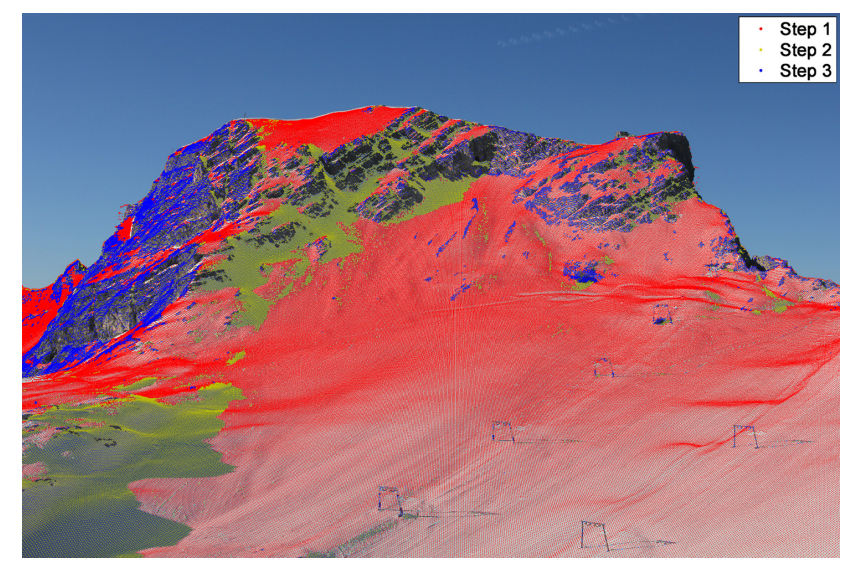

Figure 4. Stepwise classification of the SLR photograph on 17 November 2011 with the new PCA-based classification: in a first step, the algorithm of Salvatori et al. (2011) is used to classify sunlit snow (red). Then, shaded snow (yellow-green) is detected with the PCA classification, and in the third step, sunny rock (blue) is classified comparing blue and red band DN. All unclassified pixels after these steps, mainly shaded rock, are subsequently classified using the blue band DN (not shown here, see Fig. 6).

where the centre of the coordinate system is shifted to the mean value of the three-dimensional data set while the axis direction of the first PC (PC1) explains the largest variance in the data set. The axis of the second PC (PC2) is orthogonal to $\mathrm{PC} 1$ and explains the second largest variance. The axis of PC3 is again orthogonal to PC1 and PC2. Due to the decreasing explained variance in the higher components, most information of the RGB data is stored in PC1 and PC2 while PC3 mainly represents remaining noise.

For the PCA, the RGB values of all visible DEM pixels $(m)$ are standardized so that each colour column has a mean of 0 and a standard deviation of 1 (RGB $\mathbf{R}_{\mathrm{s}}$ ). The PC coefficients are calculated using a singular value decomposition. The $m \times 3 \mathbf{R G B}_{\mathrm{s}}$ matrix is then multiplied with the $3 \times 3 \mathrm{PC}$ coefficient matrix and results in the $m \times 3$ PC score matrix $\left(\mathbf{P C}_{\mathrm{sc}}\right)$, which represents the standardized RGB values in the PCA space. The $\mathbf{P C}_{\mathrm{sc}}$ has a decreasing explained variance from column 1 to $3\left(\mathbf{P C}_{\mathrm{sc}} 1\right.$ to $\left.\mathbf{P C}_{\mathrm{sc}} 3\right)$ and is normalized by scaling between 0 and 1 in a last step.

Frequency histograms of the normalized PC score matrix $\left(\mathbf{P C}_{\mathrm{sc}, n}\right)$ for the columns 1 to 3 are illustrated in Fig. 5a to c. The shape of the frequency histogram of $\mathbf{P C}_{\mathrm{sc}, n} 1$ in the PCA space (Fig. 5a) is essentially identical to the blue band DN frequency histogram in the RGB space. Hence, $\mathbf{P C}_{\mathrm{sc}, n} 1$ is not analysed further as the first classification step already utilizes this information. But the frequency histograms of $\mathbf{P C}_{\mathrm{sc}, n} 2$ and $\mathbf{P C}_{\mathrm{sc}, n} 3$ are used and play a major role in the separation of shaded snow from other surfaces. Empirical analyses of numerous photographs have shown that shaded snow pixels have higher $\mathbf{P C}_{\mathrm{sc}, n} 2$ than $\mathbf{P C}_{\mathrm{sc}, n} 3$ values (Fig. $5 \mathrm{~b}$ and c). For the used example, this means that shaded snow cover is grouped in the local maximum around 0.7 in the frequency histogram of $\mathbf{P C}_{\mathrm{sc}, n} 2$ (Fig. 5b). As a consequence, pixels are classified as snow where

$\mathbf{P C}_{\mathrm{sc}, n} 3<\mathbf{P C}_{\mathrm{sc}, n} 2 \quad$ and $\quad \mathrm{DN}_{\mathrm{b}, \text { th }} \geq \mathrm{DN}_{\mathrm{b}} \geq 63$

A blue band $\mathrm{DN}\left(\mathrm{DN}_{\mathrm{b}}\right)$ condition is additionally included as first, all pixels with $\mathrm{DN}_{\mathrm{b}}$ greater or equal to the derived snow threshold $\left(\mathrm{DN}_{\mathrm{b}, \mathrm{th}}\right)$ are already classified as snow in the first step of the routine. Second, very dark pixels in the blue band with $\mathrm{DN}_{\mathrm{b}}$ lower than one-fourth of the $\mathrm{DN}$ range (63) have been identified as prone to snow misclassifications. The snow cover derived from the PC analysis step is coloured in yellow-green in Fig. 4.

The third step of the algorithm detects sunny rocks utilizing the $\mathrm{DN}$ in the blue and the red band $\left(\mathrm{DN}_{\mathrm{r}}\right)$. Reflectance values of most rock surfaces increase from shorter to longer visible wavelengths and hence from blue to red. This characteristic can also be observed in the RGB values of the sunny rock surface in Fig. 3a. Pixels not classified in the first two steps are identified as sunny rocks for

$\mathrm{DN}_{\mathrm{r}} \geq \mathrm{DN}_{\mathrm{b}}$

The detected rock surfaces are depicted in blue in Fig. 4.

Finally, pixels not classified in the three steps before $\left(\mathrm{DN}_{\mathrm{b}, \mathrm{n}}\right)$ are assigned snow probability values $\left(P_{\mathrm{s}}\right)$ from 0 for no snow to 1 for snow linearly increasing from low to high $\mathrm{DN}_{\mathrm{b}} . P_{\mathrm{s}}$ is not a statistically derived variable but is a helpful indicator as the probability of a snow covered pixel increases with higher reflectance values in the blue spectrum. $P_{\mathrm{S}}$ is calculated using

$P_{\mathrm{s}}=\left(\frac{\mathrm{DN}_{\mathrm{b}, \mathrm{n}}-\left(\max \left(63, \min \left(\mathrm{DN}_{\mathrm{b}, \mathrm{n}}\right)\right)-1\right)}{\mathrm{DN}_{\mathrm{b}, \mathrm{th}}-\left(\max \left(63, \min \left(\mathrm{DN}_{\mathrm{b}, \mathrm{n}}\right)\right)-1\right)}\right)$.

Negative $P_{\mathrm{S}}$ values are set to 0 , no snow, as we assume that pixels with $\mathrm{DN}_{\mathrm{b}}$ below one-fourth of the $\mathrm{DN}$ range (63) are areas free of snow. It should be noted that the blue band threshold of 63 in Eqs. (3) and (5) can be adjusted by the user even though this was not necessary for any analysed photograph throughout the development of the routine.

Results of the newly implemented snow classification routine are illustrated in Fig. 6 and can be compared to the results of V1.0 in Fig. 3b. At last, we want to mention that the new routine and in particular the PC analysis step was successfully applied in at least $95 \%$ of our shadow-affected test photographs. For shadow-free situations, it is though still recommended to use the existing classification routines presented in Härer et al. (2013).

\subsection{Threshold calibration for optimal NDSI-based snow cover maps}

The new approach to automatically derive an optimal NDSIbased snow cover map is implemented in the second new 

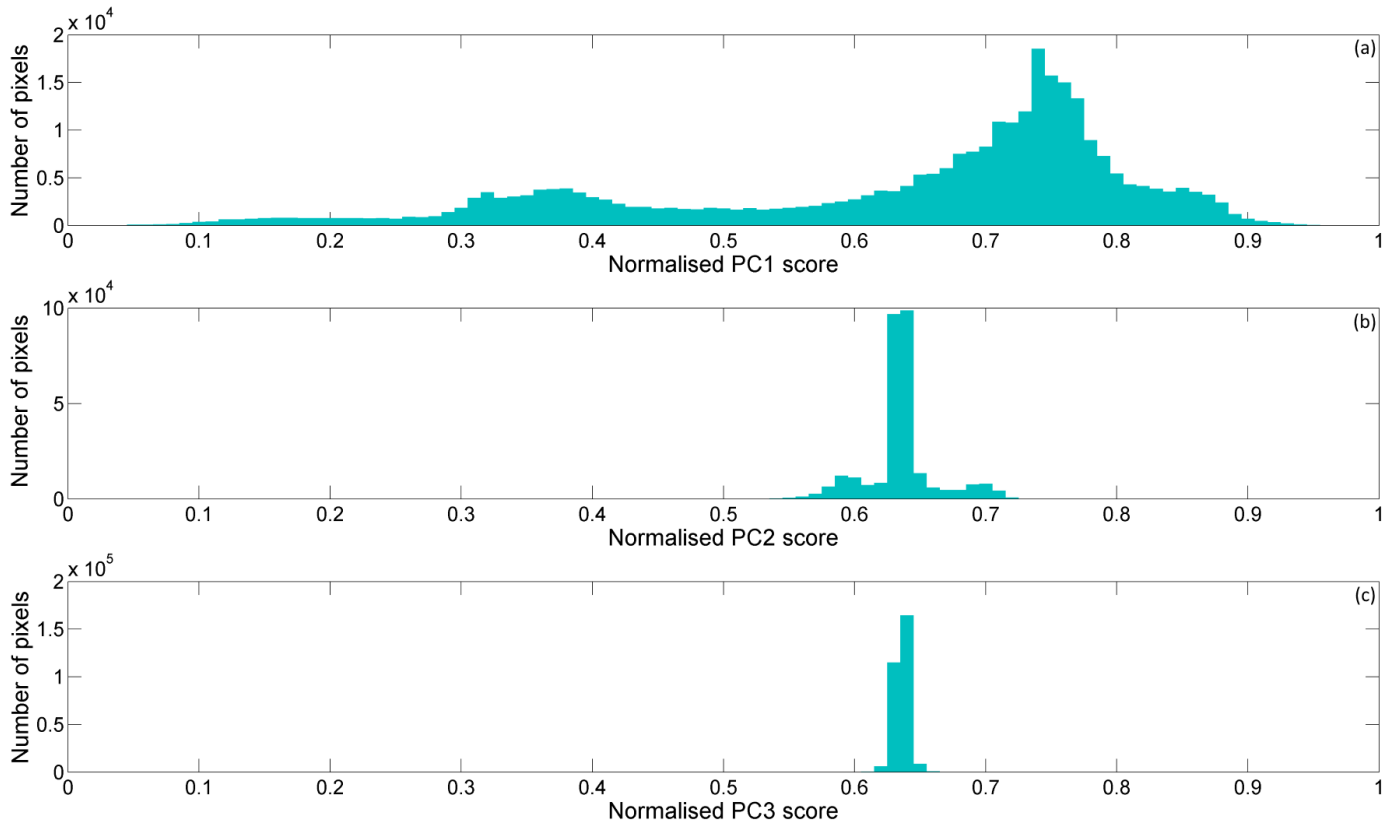

Figure 5. Frequency histograms of the normalized PC score matrix with decreasing explained variance from column 1 to 3 (PC $\mathbf{C}_{\mathrm{sc}, n} 1$ to $\mathbf{P C}_{\mathrm{sc}, n}$ 3): while the information stored in $\mathbf{P C}_{\mathrm{sc}, n} 1$ (a) is largely redundant with the information given and analysed by the blue band of the RGB space, the PCA facilitates the separation of shaded snow cover from other surfaces by comparing $\mathbf{P C}_{\mathrm{sc}, n} 2$ (b) to $\mathbf{P C}$ sc, $n 3$ (c) values using Eq. (3).

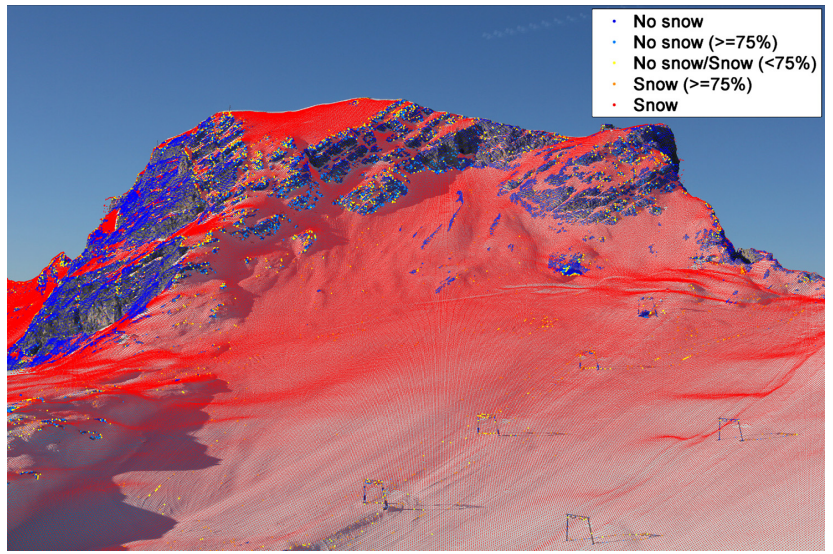

Figure 6. Results of the PCA-based classification of the SLR photograph on 17 November 2011: snow is classified in red, snow-free areas are depicted in blue. The pixels classified as probably snow (orange), probably no snow (light blue) and highly unsure (yellow) are enlarged for the sake of clarity. Only about $3.6 \%$ of all classified pixels fall within one of the three probability categories and hence are assumed as unsure.

module of PRACTISE V.2.1. The method utilizes areas that show an overlap between a photograph snow cover map and the NDSI product of a simultaneously captured satellite scene. Then, the NDSI threshold value for snow is calibrated using the dynamically dimensioned search (DDS) optimization algorithm (Tolson and Shoemaker, 2007) to obtain an optimal agreement of photograph and satellite snow cover map.

The photograph snow cover map is the ground truth data in the calibration and results from the georectification and classification of a terrestrial photograph in PRACTISE V.2.1. The NDSI map is calculated within the program evaluation for radiometrically and geometrically corrected Landsat data. The Landsat level 1 data are freely available from the archives of the US Geological Survey. The top of atmosphere planetary reflectance values of the green, near infrared, and mid-infrared bands of Landsat 5, 7, or 8 image are automatically derived from the DN in accordance to the Landsat 5 , 7 , or 8 user handbook including a correction for the sun angle. For example, for Landsat 7 imagery the metadata file and the data bands 2 (GREEN, 0.52-0.60 $\mu \mathrm{m}$ ), 4 (NIR, 0.77$0.90 \mu \mathrm{m})$, and 5 (MIR, 1.55-1.75 $\mu \mathrm{m})$ are used in here. The NDSI is calculated on the basis of the reflectance values according to Eq. (1) (Dozier, 1989; Hall et al., 1995). We want to highlight that externally produced NDSI maps from satellites like Spot, MODIS Aqua, and MODIS Terra can also be directly used.

If the Landsat scene is partially cloud covered, an externally generated cloud mask should be used to prevent misclassifications. A direct input link for the cloud mask product of the freely available Fmask software of Zhu et al. (2015) is integrated in PRACTISE to mask clouds, cloud shadows and water. The near infrared condition of Eq. (2) (Dozier, 1989; Hall et al., 1995), which is used to prevent water surfaces 
from being classified as snow is also applied here for masking strongly shaded pixels prone to misclassifications.

Overlapping areas of terrestrial photography and the satellite image are subsequently detected. The results of the photograph snow cover maps are used as a baseline. It is a user's decision if pixels classified as unsure in the photograph are excluded or used in weighted form according to their probability value. The user's selection, however, only affects the NDSI threshold calibration of the satellite image while the photograph snow cover map remains unchanged.

Now, the DDS optimization routine, which is also implemented in the framework of the GCP optimization (cf. Härer et al., 2013), is used to optimize the NDSI threshold value. The seed is set to the threshold of 0.4 , recommended by Dozier (1989), and Hall et al. (1995) and the NDSI threshold value is limited to the range of NDSI values, which can be found in the overlapping area. The number of maximum iterations is user dependent, but it was found that 150 optimization runs are sufficient. A quality measure of Aronica et al. (2002), which was successfully used in the context of snow extent evaluation in Bernhardt and Schulz (2010) serves as the objective function value $F$ in the optimization:

$F=\frac{a+d}{n}$,

$n$ is the overall number of photo-satellite image pixel pairs whereas $a$ represents the number of correctly identified snow pixels and $d$ the same for snow-free pixels. $F$ takes on values between 0 and 1 with 1 indicating a perfect agreement between the two images.

The routine is exemplarily presented for the SLR photograph of 17 November 2011 and the simultaneously captured Landsat 7 ETM+ satellite image of the Zugspitze massif. All photograph classification results from Sect. 3.1 are used in the NDSI threshold calibration. A Fmask satellite cloud mask is additionally utilized to the near infrared condition of Eq. (2) for reasons of cloud cover in the investigated area even though not visible in the Landsat Look image (Fig. 2a). Tests for several scenes of Landsat 7 and 8 have shown that masking clouds with a cloud probability of $95 \%$ and a surrounding buffer of three pixels in Fmask is reasonable in this application. The buffer secures that the satellite pixels used are not influenced by the thin edges of clouds and cloud shadows, which could potentially lead to misclassifications.

The photograph and satellite snow cover maps of the SLR photograph and the Landsat 7 ETM+ image with an optimized NDSI threshold of 0.18 are illustrated in Fig. 7. The classification agreement in the overlapping area of photograph and satellite is $97 \%$. The snow cover extent amounts to $2.8 \mathrm{~km}^{2}$ and the masked area due to shadows and clouds covers an area of $3.6 \mathrm{~km}^{2}$ for this date. The areal coverages are calculated for the alpine Zugspitzplatt catchment $\left(\sim 13.1 \mathrm{~km}^{2}\right.$, Fig. 1) defined by the catchment outlet at the Partnach spring.

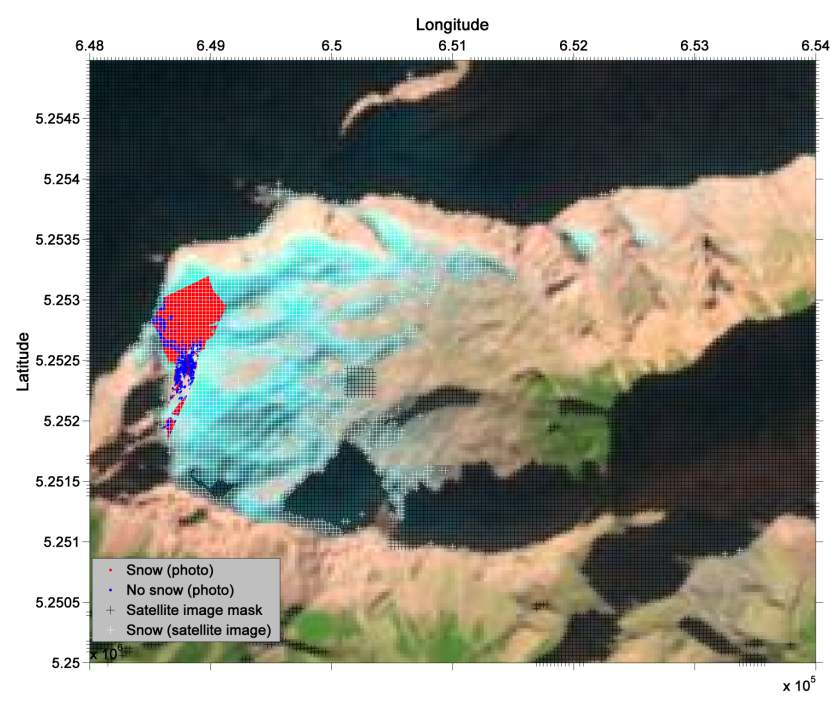

Figure 7. Resulting snow cover maps of the SLR photograph and the Landsat 7 ETM+ image on 17 November 2011 for the Zugspitze massif superimposed on the Landsat Look image: snow cover is illustrated in red and areas free of snow in blue for the photographed area. Unsure photo classification results are not shown for reasons of clarity even though used in the NDSI threshold calibration. White crosses depict snow cover in the satellite data using the calibrated NDSI threshold of 0.18 . Masked areas including clouds and shadows are displayed with black crosses. Areas in the Landsat Look image not superimposed with crosses are snow-free satellite pixels.

\subsection{Interactive modules, code improvements and the flow chart}

In addition to the two new routines (Sect. 3.1 and 3.2), the code and the user friendliness of the existing modules in PRACTISE V.2.1 have been improved.

Interactive modes are now available in the modules, $o p$ timization of the camera location and orientation and snow classification, which allows the user to directly interact with the software during runtime. Hence, the user can now interactively restart and refine the optimization of the exterior and interior camera parameters without the need to restart the complete program evaluation. The interactive mode in the snow classification module allows for switching between the three snow classification routines described in Sect. 3.1. The classification parameters for the different algorithms can also be adapted. The user can thus directly decide on the best classification method and parameters for each photograph.

PRACTISE V.2.1 is now also able to process photographs that were taken from camera locations sheltered by for example a roof and thus are assumed below ground in a DEM. In this case, surrounding DEM pixels will obstruct the view in the viewshed calculation. For omitting this problem the user can now create a radial zone around the camera location where DEM pixels are assumed transparent. In addition to the improvements mentioned here, we refer the reader to the 


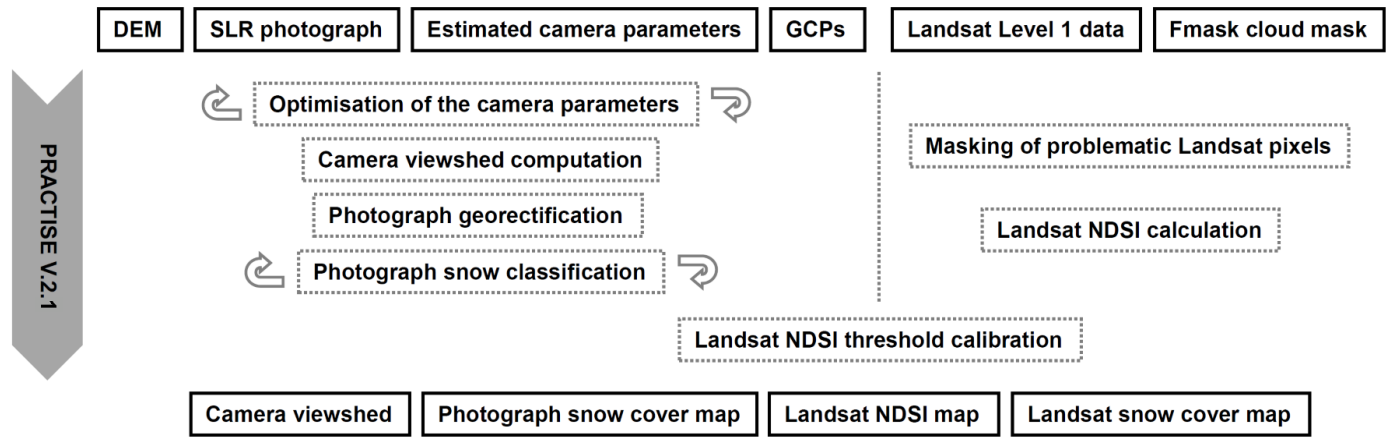

Figure 8. General flow chart of PRACTISE V.2.1 for the SLR photograph and Landsat 7 ETM+ image on 17 November 2011: inputs needed and output data generated in the PRACTISE run are depicted in solid black boxes at the top, respectively, at the bottom. All modules (dashed boxes) are active in the program evaluation and are executed downwards. Arrows illustrate activated interactive modes in the modules as the user can restart and adapt these routines during the program evaluation.

manual accompanying this paper for the description of other adaptations in the new version of PRACTISE, in particular regarding the data handling and naming conventions of input and output data.

The new routines are presented in detail for the SLR photograph and Landsat 7 ETM+ satellite image of Zugspitzplatt on 17 November 2011 (Sect. 3.1 and 3.2). Figure 8 now illustrates the general flow chart of PRACTISE V.2.1. All modules, including the new routines, are active. The program evaluation starts with the reduction of the positional inaccuracy of the GCPs by optimizing the estimated camera parameters. The user can interactively restart or refine the optimization of camera location and orientation (Sect. 3.3). Then, the viewshed is calculated for the respective camera system and the georectification procedure is executed. All visible DEM pixels are subsequently classified as snow covered or snow free by using the automatic blue band snow classification routine described in detail in Härer et al. (2013). Interactively switching to other classification routines and adapting the classification parameters is possible here (Sect. 3.1). In a next step, the NDSI is calculated for Landsat pixels, which are not masked by the NIR condition in Eq. (2) and an externally generated Fmask satellite image cloud mask (Zhu et al., 2015). Areas that are covered by terrestrial photography and satellite are eventually used to calibrate the NDSI threshold value (Sect. 3.2). Final outputs of the described PRACTISE run are snow cover maps based on the SLR photography and Landsat Level 1 data, a Landsat NDSI map and the computed viewshed.

The runtime of PRACTISE V.2.1 for this set-up with a photographed area of about $0.3 \mathrm{~km}^{2}$ and a Landsat processing extent of $30 \mathrm{~km}^{2}$ was about $58.6 \mathrm{~s}$ on an Intel Core i7$2600 \mathrm{CPU}$ with $3.4 \mathrm{GHz}$ utilizing $1.2 \mathrm{~GB}$ of memory (RAM). However, interactive modes were deactivated in the runtime measurement and hence the optimization of camera parameters with 3000 iterations $(\sim 0.58 \mathrm{~s})$ was executed only once.

\section{Results and discussion}

We have presented the functionality of PRACTISE V.2.1 in course of this paper. It incorporates all options available in PRACTISE V.1.0 with revised code and improved userfriendliness. Most important are, however, the new modules facilitating on the one hand the derivation of more reliable photography-based snow cover maps even in partially shaded areas. Furthermore, a completely new approach to create calibrated NDSI thresholds needed for the generation of snow cover maps based on satellite images was introduced.

While the new modules have been presented for a SLR photograph and a Landsat 7 ETM+ image on 17 November 2011 in Sect. 3.1 and 3.2, we evaluate the software for two dates, 1 July 2013 and 7 April 2014. SLR and webcam photographs, as well as Landsat 7 or Landsat 8 scenes of the Zugspitzplatt are available for theses dates. The scene of 1 July 2013 is partially cloud covered and therefore a Fmask satellite cloud mask was additionally utilized to the near infrared condition of Eq. (2).

In a first step, the quality of the photography-based snow cover maps was assured. The positional accuracy of the GCPs after the optimization of camera parameters is exemplarily illustrated for the SLR and webcam photographs on 7 April 2014 in Fig. 9a and b. The root mean square error (RMSE) between GCPs and control points is 0.5 and $2.2 \mathrm{~m}$, respectively. Both RMSE values are thus smaller than the spatial resolution of the DEMs used ( $1 \mathrm{~m}$ for the SLR photograph and $5 \mathrm{~m}$ for the webcam photograph). This was also confirmed for the two other dates used in this study. Further, the positional inaccuracy of the GCPs in the photographs is always smaller than in the Landsat scenes. The mean RMSE value in the presented Landsat scenes is $5.8 \mathrm{~m}$.

Misinterpretations in the georectification and as a result in the classification were only found for snow groomers and some infrastructure not represented in the DEM and viewshed. An example of these obstacles leading to misinterpretations is an antenna in the centre of the webcam photographs 


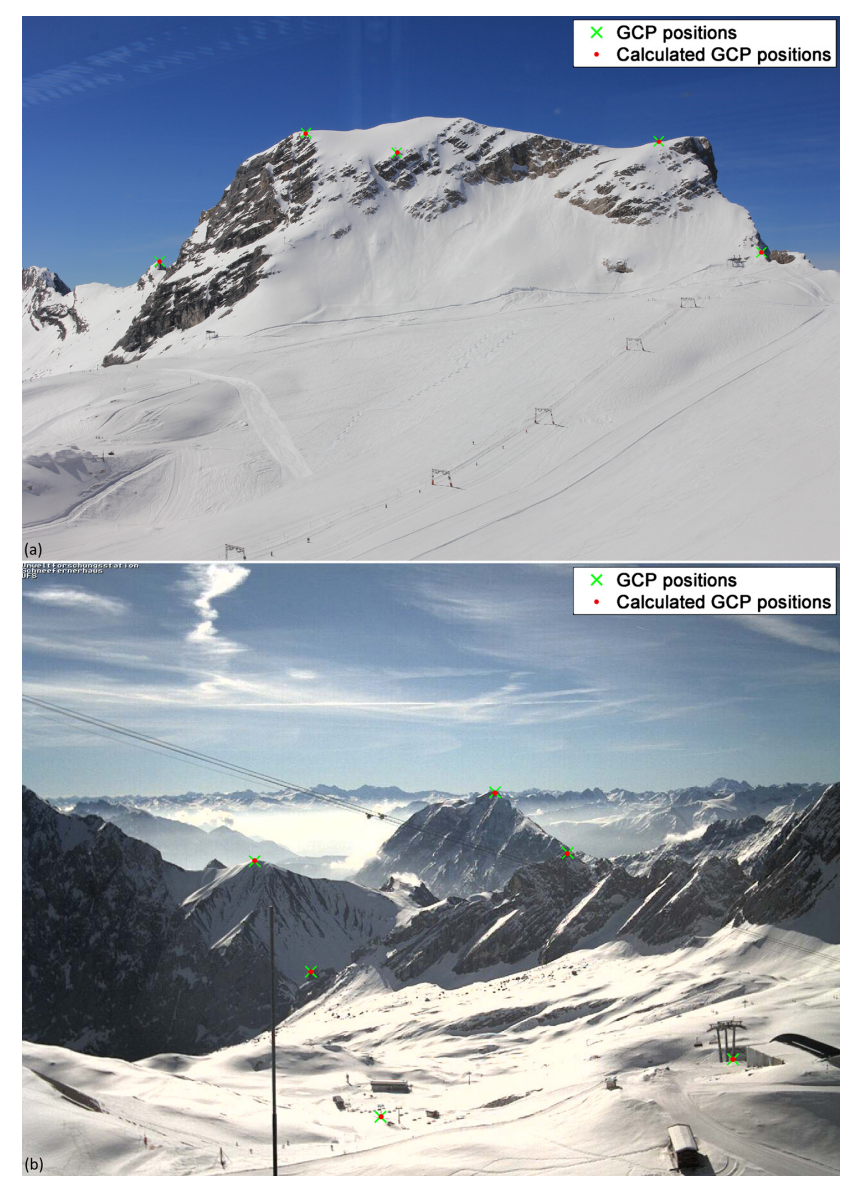

Figure 9. Real and calculated GCP positions for the investigated photographs on 7 April 2014: the root mean square error (RMSE) between real (green crosses) and calculated (red dots) GCP positions are $0.5 \mathrm{~m}$ for the SLR photograph (a) and $2.2 \mathrm{~m}$ for the webcam photograph (b) after the optimization of the camera parameters.

(cf. Fig. 9b). As the number of pixels affected by this and similar problems is less than $0.5 \%$ of the mapped area, the georectification quality of all camera images can be summarized as very high.

Figure 10a to d show the superimposed snow classifications (snow in red, no snow in blue) on the SLR and webcam photographs of 1 July 2013 and 7 April 2014. The July photographs in Fig. 10a and b do not show strong shadowing effects due to the high sun angle at this date. Hence, the automatic blue band classification algorithm was used. The resulting classification visually indicates a high quality and will not be further discussed here as the method was evaluated before in Salvatori et al. (2011) and Härer et al. (2013).

For the photographs of 7 April 2014 the PCA-based classification algorithm was applied to reduce shadow-related misclassifications (Fig. 10c and d). The detailed visual analysis of the pixels in the two April photographs showed the high quality of the new classification routine for pixels identified as snow and free of snow as well as for pixels classified as probably snow, highly unsure, and probably no snow.

Misclassifications in the main classification categories snow and free of snow are rare with less than $0.3 \%$ of classified pixels in the SLR photograph and less than $1 \%$ in the webcam photograph. The reasons for misclassifications are, however, different in both photographs. In the SLR photograph, the misclassifications can mainly be attributed to the light-coloured bare rock (limestone) in the Zugspitzplatt area, which is mistakenly classified as snow. This issue has already been discussed in detail in Härer et al. (2013, PRACTISE V.1.0) and is a weakness of the blue band classification method, which represents one of the classification steps in the PCA-based classification routine. The misclassifications in the webcam photograph have two main origins: a georectification problem due to infrastructure, which has already been mentioned above, and another problem, as shaded areas, in particular in the valley below the Zugspitzplatt, are difficult to classify as snow and no snow, even with the human eye.

In addition to the two main classification categories, the three unsure categories need to be discussed for the April photographs; $1.9 \%$ of classified pixels in the SLR photograph and $7.8 \%$ in the webcam image are assigned probability values. The low percentages emphasize that the assignment rules in the PCA-based classification routine seem to describe the RGB characteristics of the different surfaces well. In addition, most pixels classified as unsure in the SLR photograph are exactly located at the transitional area between snow patches and snow-free areas in the photographs, and can therefore be seen as mixed pixels (Figs. 10c and 11a). The classification of the SLR photograph on 17 November 2011 (Fig. 6) has also attested this finding.

In the webcam photograph, more pixels are classified as unsure in particular as probably no snow (Figs. 10d and 11b). The detailed analysis also shows some no snow misclassifications in the webcam photograph, especially in the transitional zone between sunny and shaded snow. Taken together, both issues concern less than $0.5 \%$ of the classified pixels and are only observed in the webcam photograph while the SLR photographs in TIFF-format, allowing for data compression without loss, are unaffected. The finding of more unsure classifications and the misclassification issue could be traced back to the lower image quality and the JPEG compression of the webcam image. Hence, such uncertainties and small errors have to be expected in the context of any analysis that uses JPEG images. Overall, the new classification technique separates sunny as well as shaded snow cover from other surfaces with a similar high accuracy as the blue band classification does classify equally illuminated photographs.

In a second step, the calibration of the NDSI threshold of the Landsat images was evaluated. At first, the results of the Landsat 7 ETM+ satellite image of 1 July 2013 are presented. The SLR calibrated NDSI threshold of this Landsat scene is 0.35 with $94 \%$ of the photo snow cover map 


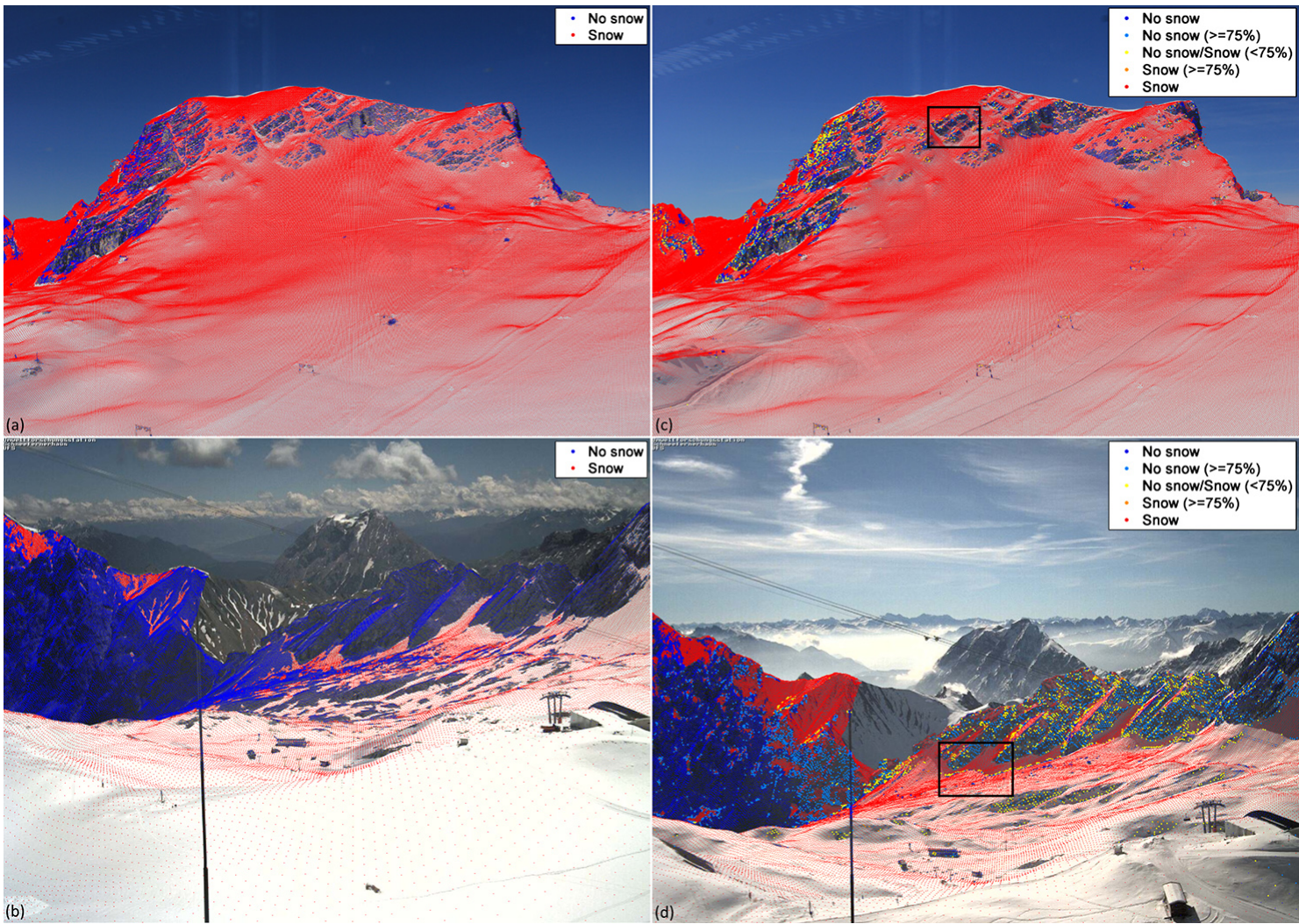

Figure 10. Superimposed snow classifications on the SLR and webcam photographs of 1 July 2013 and 7 April 2014: the SLR (a) and webcam (b) photographs of July 2013 utilized the blue band classification routine of Salvatori et al. (2011) depicting snow in red and no snow in blue. The new PCA-based classification method is, however, applied for the SLR (c) and webcam (d) photographs of April 2014. Here, snow and snow-free pixels are again displayed in red and blue but additionally unsure classification results are illustrated in light blue, yellow and orange for the categories probably no snow, highly unsure, and probably snow. Black rectangle boxes in (c) and (d) are depicted for detailed analyses of the classification accuracy (Fig. 11a and b).

being identical to the calibrated satellite image snow cover map. The calibration of the NDSI threshold using the webcam photograph results in a threshold of 0.37 . Here, the classification agreement of the snow cover is with $84 \%$ slightly lower but still high. In the Landsat 8 OLI satellite image of 7 April 2014, the NDSI threshold optimized with the SLR photograph is 0.23 (94\% agreement). An identical NDSI threshold of 0.23 (90\% agreement) was found for the simultaneously captured webcam photograph. The snow cover maps from the SLR and webcam photographs as well as from the SLR calibrated satellite images are depicted in Fig. 12a for 1 July 2013 and in Fig. 12b for 7 April 2014. The SLR derived snow covered area in the Zugspitzplatt catchment amounts to $6.5 \mathrm{~km}^{2}$ for the July date, respectively $9.9 \mathrm{~km}^{2}$ for the April date. Masked areas are $1.3 \mathrm{~km}^{2}$ on 1 July 2013 and $0.9 \mathrm{~km}^{2}$ on 7 April 2014 due to shadows and clouds.

We want to emphasize here that the percentage of pixels identically classified in photograph and satellite image maps is enormously high, keeping in mind the different horizontal resolutions of photograph map (SLR: $1 \mathrm{~m}$, webcam:
$5 \mathrm{~m})$ and satellite image map $(30 \mathrm{~m})$. The resolution effect becomes more pronounced for patchier snow cover, in this case in the lower Zugspitzplatt area, which also explains the slightly lower agreement between webcam photograph and satellite image.

Another important finding is that the calibration of the NDSI threshold using SLR and webcam results in almost identical NDSI thresholds. As the differences are insignificant the NDSI threshold calibration seems to be robust in the Zugspitzplatt area independent of the used camera system and field of view.

At last, the changing NDSI thresholds of 0.18 on 17 November 2011, 0.35 on 1 July 2013, and 0.23 on 7 April 2014 calibrated with the SLR camera need to be discussed. All thresholds are below the value of 0.4 from Dozier (1989) and Hall et al. (1995) and the increases of snow cover extent in the Zugspitzplatt catchment are between $3.7 \%$ on 1 July 2013 and $26.7 \%$ on 17 November 2011 using the calibrated NDSI threshold values instead of the literature value of 0.4. Consequently, larger differences between the 


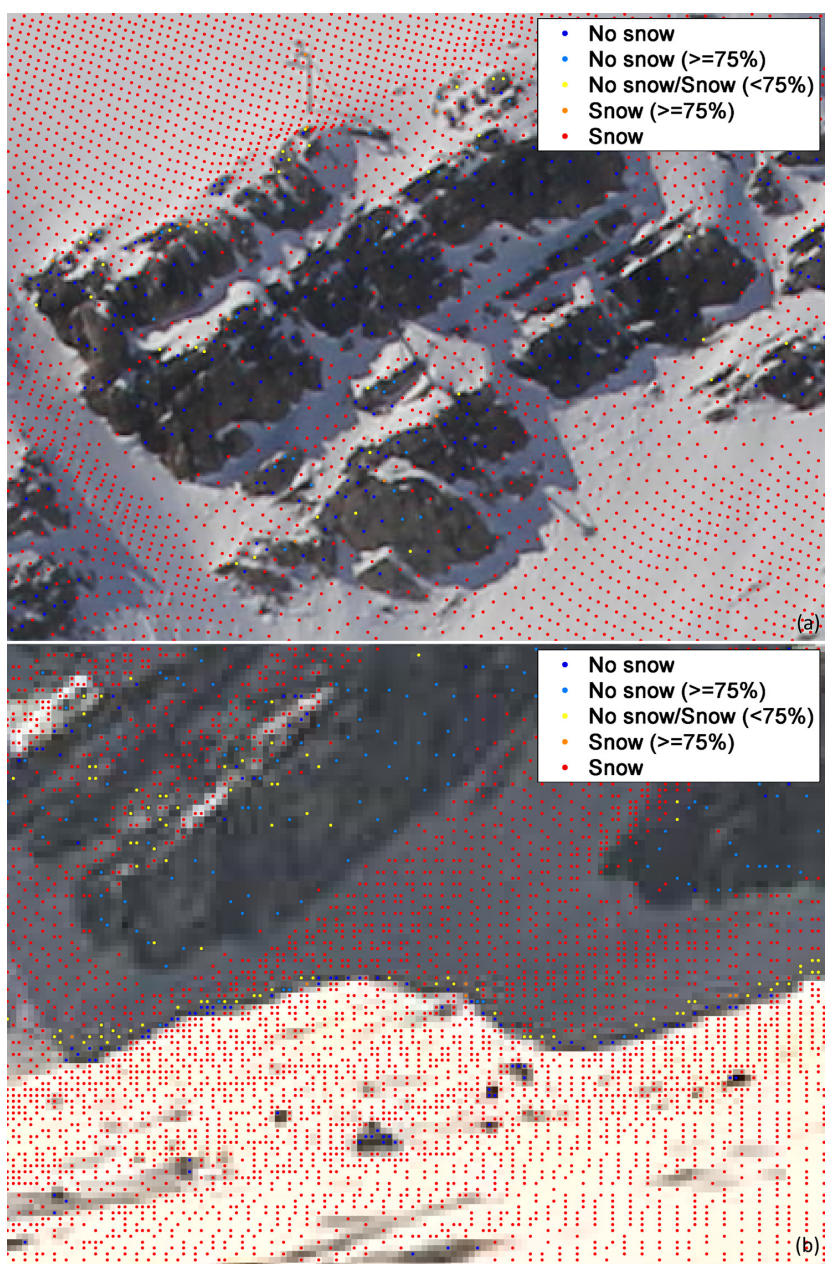

Figure 11. Enlarged view of the superimposed snow classifications on the SLR and webcam photographs of 7 April 2014 (rectangle boxes in Fig. 11c and d): (a) unsure classification results in the SLR photograph are located at transitional areas between snow patches and snow-free areas. (b) In the webcam photograph, more pixels are classified in the three unsure categories. Moreover, some no snow misclassifications are found at the transitional zone between sunny and shaded snow cover.

optimized and the standard NDSI threshold value lead to a higher percentage change of snow cover.

Figure 13a to $\mathrm{c}$ display the optimized snow cover maps (light blue) in the Zugspitzplatt for the three investigated dates in chronological order. They are superimposed with the standard snow cover maps (dark blue). The visual comparison of the snow cover maps clearly shows that especially the edges of the snow cover are reclassified to snow whereas no new large snow patches are identified. This demonstrates on the one hand that the core snow cover areas are already correctly classified using the standard threshold. On the other hand this result also highlights that Landsat snow pixels at the snow cover edge, and hence probably mixed pixels, rep-
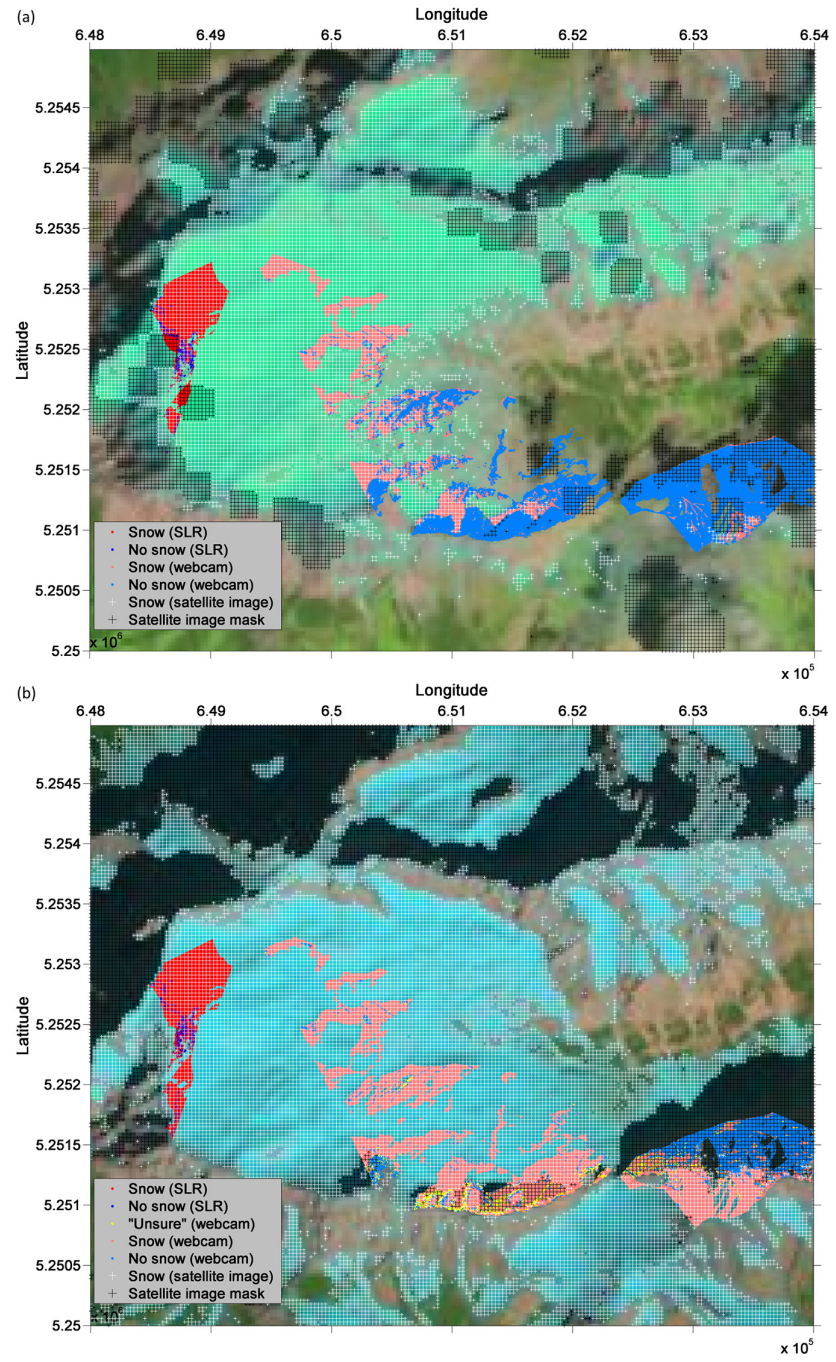

Figure 12. Resulting snow cover maps of the SLR and webcam photographs, and the Landsat images for the Zugspitze massif superimposed on the Landsat Look images: the satellite snow cover maps are calibrated using the SLR snow cover maps as baseline. The resulting NDSI thresholds are 0.35 for 1 July 2013 (a) and 0.23 for 7 April 2014 (b). Snow cover in the satellite data is illustrated with white crosses, masked areas with black crosses mainly due to clouds in (a) and shadows in (b). Pixels not superimposed with crosses are areas classified as free of snow in the satellite images. The photograph snow cover maps display snow and no snow in red and blue for the SLR and in light red and light blue for the webcam. Unsure snow classification results only occur for the photographs on 7 April 2014 (b) as the PCA-based classification routine is applied and are only shown for the webcam (yellow) as the percentage of unsure snow classifications in the SLR photograph (Figs. 10c and 11a) is negligible.

resent a substantial portion of snow cover in alpine areas and thus have to be correctly classified for optimum results.

In addition to the visual analysis, we analysed changes in the elevation distribution of snow covered pixels in the 


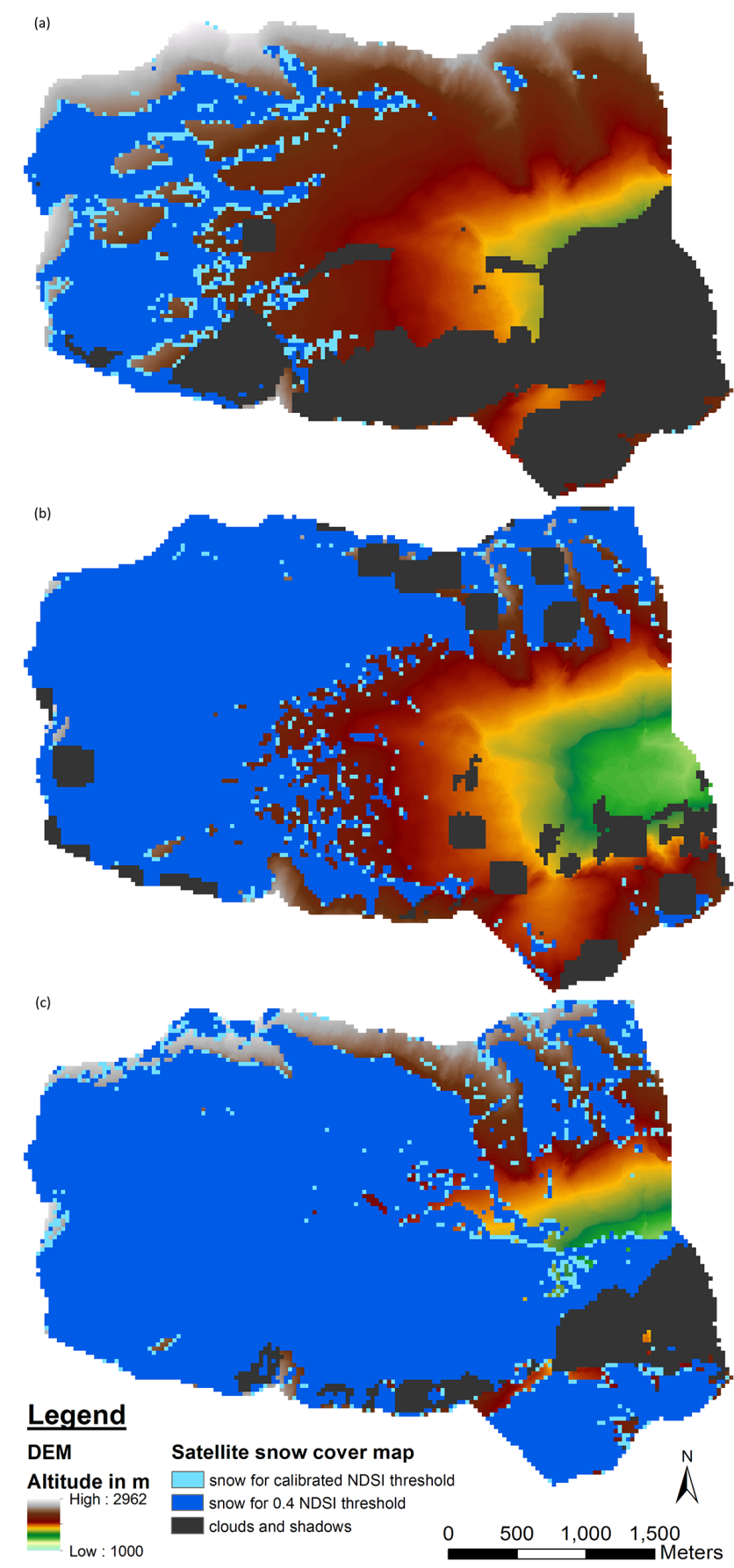

Figure 13. Standard and optimized snow cover maps of the Zugspitzplatt catchment for 17 November 2011 (a), 1 July 2013 (b), and 7 April 2014 (c): snow cover extents using the standard NDSI threshold value of 0.4 are depicted in dark blue, additionally detected snow cover using the SLR calibrated NDSI threshold values of 0.18 (a), 0.35 (b), and 0.23 (c) in light blue, and clouds and shadows in dark grey. The snow cover maps are superimposed on the DEM of the investigation area (cf. Fig. 1).
Zugspitzplatt area, in particular of the lower elevation snow cover. As the lowest elevation where snow cover is detected is not necessarily representative for the current snow cover distribution in the investigation area, the $10 \%$ quantile of the elevation values of snow covered pixels was calculated. The resulting elevations for the $10 \%$ quantile are $2390.6 \mathrm{~m}$ on 17 November 2011, 2261.4 m on 1 July 2013, and $1948.8 \mathrm{~m}$ on 7 April 2014 for the literature NDSI threshold, and, respectively, 2352.1, 2251.5, and $1938.6 \mathrm{~m}$ for the optimized NDSI thresholds. The elevation differences between the standard and the optimized method consequently range between $9.9 \mathrm{~m}$ for the July date and $38.5 \mathrm{~m}$ for the November date. The increase of snow covered areas in lower elevations using the lower optimized NDSI threshold values might be expected. However, about $10 \mathrm{~m}$ and in an extreme case about $40 \mathrm{~m}$ elevation change in lower elevation snow cover can make a huge difference, for example, when applied in climate change studies.

The presented values and findings underline that the strong temporal variations found in NDSI thresholds transfer to large uncertainties in the derivation of snow cover extents and studies relying on these snow cover products. A spatial and temporal adjustment of NDSI thresholds is therefore important to ensure optimum results in the snow cover mapping of specific areas, for example of the studied alpine catchment.

\section{Conclusion and outlook}

PRACTISE V.2.1 was already in the previous version a fast and user-friendly tool to georectify and classify photographs, but now further provides a new and objective method to automatically calibrate NDSI thresholds in satellite images and thus to create reliable, spatially, and temporally specific NDSI-based satellite snow cover maps. The snow classification of photographs has moreover become more flexible with the additional opportunity to classify partially shadowaffected photographs. The code of the old version has additionally been revised and the user-friendliness has been improved while the functionality of all existing routines in PRACTISE V.1.0 remained.

PRACTISE V.2.1 is thus a simple- and ready-to-use software tool that was developed and tested for SLR and webcam photographs, as well as Landsat 7 ETM+ and Landsat 8 OLI satellite images in the Zugspitzplatt area. The successful use of webcam photographs in the calibration of the NDSI threshold of a Landsat 7 as well as a Landsat 8 scene further increases the transferability of this study to other areas. Obviously when using freely available webcam infrastructure, the processing of PRACTISE needs an increased attention for any problems that may arise in the snow mapping due to image quality, lens distortion, and obstacles in the field of view.

Our next step will be to apply PRACTISE and the integrated new approach to the complete available time series of photographs and satellite images in the Zugspitzplatt area. 
In addition, we will process another long-term time series of photographs in the alpine Vernagtferner area, Austria, which is located in the same Landsat scene as the Zugspitzplatt. We think that this experimental set-up will be a first step towards understanding the temporal variability of the calibrated NDSI thresholds in alpine areas. Furthermore, the setup will also allow for testing spatial representativeness of the optimal NDSI threshold on the regional scale as this is another topic of ongoing discussion. This will be especially important as the spatio-temporal extrapolation possibilities and limits of the presented method are as yet unknown. Further research will also be necessary to verify if the synthesis of terrestrial photograph and satellite image is applicable in a modified form to other research fields like thermal photography and satellite imagery.

\section{Code availability}

The source code of PRACTISE V.2.1 is distributed under the Creative Commons license (CC-BY-NC-SA 4.0) and together with a manual and an example data set available online here: https://github.com/shaerer/PRACTISE/releases/tag/v2. 1 (doi:10.5281/zenodo.35646).

The software is executable on any Windows or UNIX computer with a basic Matlab installation and at least $2 \mathrm{~GB}$ RAM. This means no additional Matlab packages are needed. Additionally, the current version of PRACTISE is also executable on Linux platforms using (64 bit-enabled) Octave 4.0 and higher, an open-source alternative of Matlab. The code has been tested for compatibility with Matlab versions from 2005 and 2015 (both Windows 7) as well as Octave 4.0 (Linux Mint 17.1 and Ubuntu 14.04). We want to note here that the code is not executable using Octave 4.0 for Windows at the moment. The reason for that is simply that no precompiled 64 bit-version of Octave 4.0 is available for Windows yet, which is though necessary to process large arrays in PRACTISE.

Please visit http://creativecommons.org/licenses/by-nc-sa/ 4.0 for further information on the used Creative Commons license and https://gnu.org/software/octave for information on GNU Octave.

Acknowledgements. The work described in this paper was supported by the doctoral scholarship program "Deutsche Bundesstiftung Umwelt" (DBU), the Helmholtz Research School "Mechanisms and Interactions of Climate Change in Mountain Regions" (MICMoR) and the Environmental Research Station Schneefernerhaus (UFS), as well as our previous palace of employment the Department of Geography at the LMU Munich. We also thank David Morche for providing the DEM, Michael Weber for occasional maintenance of the SLR camera, and Ben Müller, Nick Rutter and Karl-Friedrich Wetzel for thoughtful discussions.

Edited by: R. Sander

\section{References}

Aronica, G., Bates, P. D., and Horrit, M. S.: Assessing the uncertainty in distributed model predictions using observed binary pattern information within GLUE, Hydrol. Process., 16, 2001-2016, doi:10.1002/hyp.398, 2002.

Aschenwald, J., Leichter, K., Tasser, E., and Tappeiner, U.: Spatiotemporal landscape analysis in mountainous terrain by means of small format photography: a methodological approach, IEEE T. Geosci. Remote, 39, 885-893, doi:10.1109/36.917917, 2001.

Bernhardt, M. and Schulz, K.: SnowSlide: a simple routine for calculating gravitational snow transport, Geophys. Res. Lett., 37, L11502, doi:10.1029/2010GL043086, 2010.

Bernhardt, M., Schulz, K., Liston, G. E., and Zängl, G.: The influence of lateral snow redistribution processes on snow melt and sublimation in alpine regions, J. Hydrol., 424-425, 196-206, doi:10.1016/j.jhydrol.2012.01.001, 2012.

Bernhardt, M., Härer, S., Jacobeit, J., Wetzel, K. F., and Schulz, K.: The virtual alpine observatory - research focus Alpine hydrology, Hydrol. Wasserbewirts., 58, 241-243, 2014.

Blöschl, G., Kirnbauer, R., and Gutknecht, D.: Distributed snowmelt simulations in an Alpine catchment: 1. model evaluation on the basis of snow cover patterns, Water Resour. Res., 27, 3171-3179, doi:10.1029/91WR02250, 1991.

Brown, R. D. and Mote, P. W.: The response of Northern Hemisphere snow cover to a changing climate, J. Climate, 22, 21242145, doi:10.1175/2008JCLI2665.1, 2009.

Corripio, J. G.: Snow surface albedo estimation using terrestrial photography, Int. J. Remote Sens., 25, 5705-5729, doi:10.1080/01431160410001709002, 2004.

Corripio, J. G., Durand, Y., Guyomarc'h, G., Mérindol, L., Lecorps, D., and Pugliése, P.: Land-based remote sensing of snow for the validation of a snow transport model, Cold Reg. Sci. Technol., 39, 93-104, doi:10.1016/j.coldregions.2004.03.007, 2004.

Dietz, A. J., Kuenzer, C., Gessner, U., and Dech, S.: Remote sensing of snow - a review of available methods, Int. J. Remote Sens., 33, 4094-4134, doi:10.1080/01431161.2011.640964, 2012.

Dozier, J.: Spectral signature of alpine snow cover from the landsat thematic mapper, Remote Sens. Environ., 28, 9-22, doi:10.1016/0034-4257(89)90101-6, 1989.

Dumont, M., Arnaud, Y., Six, D., and Corripio, J. G.: Retrieval of glacier surface albedo using terrestrial photography, Houille Blanche, 2, 102-108, doi:10.1051/Lhb/2009021, 2009.

Garvelmann, J., Pohl, S., and Weiler, M.: From observation to the quantification of snow processes with a time-lapse camera network, Hydrol. Earth Syst. Sci., 17, 1415-1429, doi:10.5194/hess-17-1415-2013, 2013.

Groisman, P. Y., Karl, T. R., and Knight, R. W.: Observed impact of snow cover on the heat balance and the rise of continental spring temperatures, Science, 263, 198-200, doi:10.1126/science.263.5144.198, 1994.

Hall, D. K. and Riggs, G. A.: Accuracy assessment of the MODIS snow products, Hydrol. Process., 21, 1534-1547, doi:10.1002/hyp.6715, 2007.

Hall, D. K., Riggs, G. A., and Salomonson, V. V.: Development of methods for mapping global snow cover using moderate resolution imaging spectroradiometer data, Remote Sens. Environ., 54, 127-140, doi:10.1016/0034-4257(95)00137-P, 1995. 
Hall, D. K., Riggs, G. A., Salomonson, V. V., Barton, J. S., Casey, K., Chien, J. Y. L., DiGirolamo, N. E., Klein, A. G., Powell, H. W., and Tait, A. B.: Algorithm theoretical basis document (ATBD) for the MODIS snow- and sea ice-mapping algorithms, available at: http://modis-snow-ice.gsfc.nasa.gov/?c= atbd\&t=atbd (last access: 30 July 2015), 2001.

Härer, S., Bernhardt, M., Corripio, J. G., and Schulz, K.: PRACTISE - Photo Rectification And ClassificaTIon SoftwarE (V.1.0), Geosci. Model Dev., 6, 837-848, doi:10.5194/gmd-6-837-2013, 2013.

Hinkler, J., Pedersen, S. B., Rasch, M., and Hansen, B. U.: Automatic snow cover monitoring at high temporal and spatial resolution, using images taken by a standard digital camera, Int. J. Remote Sens., 23, 4669-4682, doi:10.1080/01431160110113881, 2002

IPCC: Climate Change 2013: The Physical Science Basis, Contribution of Working Group I to the Fifth Assessment Report of the Intergovernmental Panel on Climate Change, edited by: Stocker, T. F., Qin, D., Plattner, G.-K., Tignor, M., Allen, S. K., Boschung, J., Nauels, A., Xia, Y., Bex, V., and Midgley, P. M., Cambridge University Press, Cambridge, UK and New York, NY, USA, 1535 pp., 2013.

Klemes, V.: The modelling of mountain hydrology: the ultimate challenge, IAHS-AISH P., 190, 29-43, 1990.

Lehning, M., Völksch, I., Gustafsson, D., Nguyen, T. A., Stähli, M., and Zappa, M.: ALPINE3D: a detailed model of mountain surface processes and its application to snow hydrology, Hydrol. Process., 20, 2111-2128, doi:10.1002/Hyp.6204, 2006.

Liston, G. E. and Elder, K.: A distributed snow-evolution modeling system (SnowModel), J. Hydrometeorol., 7, 1259-1276, doi:10.1175/JHM548.1, 2006.

Marty, C.: Regime shift of snow days in Switzerland, Geophys. Res. Lett., 35, L12501, doi:10.1029/2008GL033998, 2008.

Messerli, A. and Grinsted, A.: Image georectification and feature tracking toolbox: ImGRAFT, Geosci. Instrum. Method. Data Syst., 4, 23-34, doi:10.5194/gi-4-23-2015, 2015.

Nolin, A. W.: Recent advances in remote sensing of seasonal snow, J. Glaciol., 56, 1141-1150, doi:10.3189/002214311796406077, 2010.

Parajka, J., Haas, P., Kirnbauer, R., Jansa, J., and Blöschl, G.: Potential of time-lapse photography of snow for hydrological purposes at the small catchment scale, Hydrol. Process., 26, 3327-3337, doi:10.1002/Hyp.8389, 2012

Pomeroy, J., Bernhardt, M., and Marks, D.: Water resources: research network to track alpine water, Nature, 521, 32, doi:10.1038/521032c, 2015.
Rivera, A., Corripio, J. G., Brock, B., Clavero, J., and Wendt, J.: Monitoring ice-capped active volcan Villarrica, southern Chile, using terrestrial photography combined with automatic weather stations and global positioning systems, J. Glaciol., 54, 920-930, doi:10.3189/002214308787780076, 2008.

Salvatori, R., Plini, P., Giusto, M., Valt, M., Salzano, R., Montagnoli, M., Cagnati, A., Crepaz, G., and Sigismondi, D.: Snow cover monitoring with images from digital camera systems, Ital. J. Remote Sens., 43, 137-145, doi:10.5721/ItJRS201143211, 2011.

Scherrer, S. C., Appenzeller, C., and Laternser, M.: Trends in Swiss Alpine snow days: the role of local- and largescale climate variability, Geophys. Res. Lett., 31, L13215, doi:10.1029/2004GL020255, 2004.

Schmidt, S., Weber, B., and Winiger, M.: Analyses of seasonal snow disappearance in an alpine valley from micro- to mesoscale (Lötschental, Switzerland), Hydrol. Process., 23, 10411051, doi:10.1002/hyp.7205, 2009.

Tolson, B. A. and Shoemaker, C. A.: Dynamically dimensioned search algorithm for computationally efficient watershed model calibration, Water Resour. Res., 43, W01413, doi:10.1029/2005wr004723, 2007.

Viviroli, D., Dürr, H. H., Messerli, B., Meybeck, M., and Weingartner, R.: Mountains of the world, water towers for humanity: typology, mapping, and global significance, Water Resour. Res. 43, W07447, doi:10.1029/2006WR005653, 2007.

Viviroli, D., Archer, D. R., Buytaert, W., Fowler, H. J., Greenwood, G. B., Hamlet, A. F., Huang, Y., Koboltschnig, G., Litaor, M. I., López-Moreno, J. I., Lorentz, S., Schädler, B., Schreier, H., Schwaiger, K., Vuille, M., and Woods, R.: Climate change and mountain water resources: overview and recommendations for research, management and policy, Hydrol. Earth Syst. Sci., 15, 471-504, doi:10.5194/hess-15-471-2011, 2011.

Watt, A. and Watt, M.: Advanced Animation and Rendering Techniques: Theory and Practice, ACM Press, New York, NY, USA, 472 pp., 1992.

Winstral, A. and Marks, D.: Simulating wind fields and snow redistribution using terrain-based parameters to model snow accumulation and melt over a semi-arid mountain catchment, Hydrol. Process., 16, 3585-3603, doi:10.1002/hyp.1238, 2002.

Zhu, Z., Wang, S., and Woodcock, C. E.: Improvement and expansion of the Fmask algorithm: cloud, cloud shadow, and snow detection for landsats 4-7, 8, and sentinel images, Remote Sens. Environ., 159, 269-277, doi:10.1016/j.rse.2014.12.014, 2015. 